\title{
The Value of Music in Children's Enlightenment Education
}

\author{
Jue Zhou \\ College of Arts, Chongqing University, Chongqing, China \\ Email: zhoujue2010@yeah.net
}

Received 23 November 2015; accepted 26 December 2015; published 29 December 2015

Copyright (C) 2015 by author and Scientific Research Publishing Inc.

This work is licensed under the Creative Commons Attribution International License (CC BY). http://creativecommons.org/licenses/by/4.0/

cC) (i) Open Access

\begin{abstract}
A large number of theories and experiments have shown that music plays positive effect on children's growth. Children who have received music education often show outstanding creativity and imagination in their school lives, compared with their peers who have not get any musical training. Just as famous educator Dr. Hans Gunther Bastian has once proposed: "music makes people smart". Learning music can not only improve children's intelligence and morality which contributes to the development of their personality, but also can improve their aesthetic ability. Cultivate music to children is an essential progress to promote all-ground education.
\end{abstract}

\section{Keywords}

\section{Music Education, Children Enlightenment}

\section{Introduction}

Music education is an indispensable part of quality education. It is a kind of aesthetic education. It is a unique form of music art. It is not only a kind of music knowledge and skills training, but also in accordance with the special law of the music art to carry out educational activities. In recent years, the music education in our country has gradually been valued by people. "The State Council on the current development of pre-school education, a number of opinions” pointed out that: pre-school education is the beginning of lifelong learning, it is an important part of the national education system, and important social welfare undertakings, run school education, the relationship between the health of millions of children, the vital interests of thousands families, the relationship between the country and the nation's future [1].

Early childhood education refers to the implementation of the 3 - 6-year-old child care and education. Preschool education is the starting point of a person's lifelong education, but also the starting point of quality education. Early childhood education generally contains three aspects: family education, social education and kin- 
dergarten education [2]. Kindergarten education is borne by the kindergarten, by professional educators according to the need of the society, for children in the garden, planned, organized to promote the all-round development of their physical and mental activities. It is an important part of basic education. The characteristics of kindergarten education are: the comparison about teaching of the teachers in the professional experience. The group activities are beneficial to the children's mutual exchange and inspiration. It is an indispensable part of the education of children, but it is closely related with the family education and social education.

Music education in kindergarten is a very special education field, which is different from the ordinary school music education, but also different from other courses. On early childhood education music enlightenment, we must foster children to music hobby and children's music comprehension adopting lively teaching content and form; it is one of the contents of aesthetic education. With the means of emotional education for children, the power of education is better than simply imparting knowledge and information. Children's music education in general was from the children's games. The pleasure of the activity began to enter the emotional experience, and then rose to the aesthetic experience. Former Soviet educator Sue Home Linksys said: "the music education is not to train musician, the first is to cultivate people [3]." Music education is an important part of early childhood education, which has an important influence on the growth and development of children.

\section{Content of Music Education about Young Children}

\subsection{Children's Singing}

\subsubsection{The Development of Children's Singing Ability}

Children's singing ability is based on the ability of children's language pronunciation. When the baby grows to 8 months or so, it will gradually imitate adult speech. 1 year old can make a different sound, the adult is not easy to listen to the specific content of the baby, but we can from the tone of his voice, the intensity of the tone to guess its meaning. To about 3 years old, you can sing some short songs, but not necessarily understand the content of the lyrics, often sing off and off the word, pronunciation is not necessarily accurate. After entering the kindergarten, children can basically distinguish the intensity, the volume of different [4]. 5-year-old children of rhythm and intonation of cognitive ability improved, grasp of rhythm is relatively accurate, the breath of singing master can learn in accordance with the phrase for ventilation, especially in singing ability of creative will not only perform under the teacher's request, and in the happy time with expression humming the songs of joy. 6year-old children can sing complete songs, they have more clear pronunciation, for the dotted and syncopated rhythm also has the certain mastery, singing expression are more abundant and showed different volume and velocity variation in the same song. Anyway, children's singing ability is along with the age increasing range from narrow to wide, rhythm from single to rich, pitch by free to accurately, music from the fragments into complete, all aspects are with physical and mental development and progress.

\subsubsection{The Basic Form of Singing and the Cultivation of the Sense of Music}

According to the number of the concert and the performance of the way, the kindergarten can be divided into the following types of singing:

Solo: an individual singing or sing. Is generally reflected in the personality is more cheerful and strong ability of the children alone.

Sing: play some of the character to drive some of the little friends of the emotions, a model of nature.

Sing: two or more than two people together in order to sing the same song songs, it is collective singing activities for kids. Unison process can enable children to help each other, inspire and lead the children ability, self-confidence is weak, learn slower, and so that children have a sense of collective.

Duet: between the individual and the individual, team and group way to sing songs in their questions and answers. Can enhance the emotional exchanges between young children, there is performance, competitive, creative, inspiring children's creative ability.

The lead singer singing: a person (or persons) the main part of the song, sing the song with the part of the collective.

The cultivation of children's music is mainly from two aspects to consider:

One is the cultivation of rhythm. Rhythm is the perception and expression of rhythm and rhythm in singing materials. The cultivation of rhythm of the music should pay attention to the rhythm of movement training, and the rhythm of the music in the song, with the rhythm of musical instruments training, attention to language 
rhythm training [5]. Active is the nature of children, children in the process of learning songs, often use body movements to express themselves, singing the song "Diu Shoo Juan" is a song rhythm is more obvious in the song. In the process of listening to the song, the teacher can stimulate children to follow the rhythm of the rhythm of the melody. Two is the melody feeling's training [6]. In children's singing skills, intonation is actually the most difficult to grasp and singing, it will be out of tune of the phenomenon is relatively common, the cultivation of sense of melody is how to enable children to sound level have the right concept.

\subsubsection{Singing Material}

We need write special songs for young children. The lyrics must be simple and easy, to make children understand the content [7]. Language should be lively and interesting, so as to attract children's interest, too deep and children's life away from the content, the children are not easy to accept. There are many songs are selected from the animals or children of parts of the body like the lyrics, children are easy to understand, but also help the children in singing to show their body movements. By this way, children can achieve better results. Good lyrics can also inspire children's imagination and performance more fully, and promote the coordination of body movements.

Secondly, we should carry out the selection of the melody, but also emphasize the simple and the beautiful melody of national characteristics. No matter how to convey the modality, we can't ignore the children's aesthetic temperament and interest of the purpose of the cultivation. The range should not be too wide, combined with the tone of life. Speed is not too fast, to medium speed too fast or medium speed, because children's breath is short, phrase should not be too long. To do short structure, without losing the work integral, otherwise it will cause children articulation inspiratory confusion and sing songs. The whole piece of music also should not be too long, the bottom class in a kindergarten to four phrases is appropriate. Help children learn songs, rhythm should not be too complex, dominated by half note, quarter notes and eighth notes, a small amount of dotted rhythm can also be appropriate use.

\subsection{Rhythmic Activity}

\subsubsection{The Development of Children's Prosodic Activity}

Germany, a famous music educator in Orff's said: music education should be started in action, in children's music education, body movements and music is closely linked, the two can't be missing, because the action is a way children express thoughts and feelings of the most direct. Action is the baby of the earliest heart activity, early before birth start acting, many pregnant women will feel baby kicking themselves [8]. These are the performance of the baby's movement, and the infant laying in the cradle, many mothers will be something like wind chimes hanging in the baby bed, children sometimes with bells swinging and rotating the eyes or hands unconscious disorderly sway. These actions are instinctive reaction. Children tend to react to their own perception of the action; the child's psychology is in the process of the main activities of the game as the main way of continuous development [9]. In 1981 Gilbert in a US study found, that children the most basic movement forms appear in before the age of five, we can at least from which a conclusion is drawn: develop children's Eurhythmics ability is an important part of childhood music practice. In the expression of the action, the children also began to pay attention to the use of action and communication, from which we can see the children's awareness of the cooperation of the germination. Listen to the music, children's body began to dance to the music, can also be seen from the children's creation consciousness, this with the creation of the teachers need sorting, refining, which is the development of children's creative. Anyway, the development of children's ability of rhythmic activity is physiological and psychological mutual development process, for children of step by step guide and education can better help children accumulate the movement vocabulary.

\subsubsection{The Basic Types of Rhythmic Activities: Rhythm, Dance and Music Games}

Rhythm is refers to the rhythmic activity in the accompaniment of music, make the action in conformity with the music beats, rhythm, moods, can use action to express music art beauty. Dance is the art of action, it is the art of human action to create the image, to express feelings, reflect social life. Children dance needs to comply with the basic rules and characteristics, but at the same time to meet the physical and psychological development of children's physical, psychological development characteristics, reflect the children's life, with the activities of children's activities. At the stage of preschool children can be divided into: dance, dance, dance, dance invita- 
tion. Such as the song "looking for friends" music game refers to activities and games in the accompaniment of music, let the children in a lively and interesting game experience of music. They live active, easy to transfer interest. Arouse children's interest is to mobilize the enthusiasm and initiative of the important premise. Famous children's educator Chen He Qin points out: music can cultivate people's personality and emotion. It also can inspire people's initiative [10]. We should create a scene for the children, to cultivate children's interest in music. The game is in line with the psychological characteristics of children, games are children's work, games are children's life in the game, and the child is always in a positive state, to get a pleasant emotional experience, but also to develop the creativity, and promote the development of children's psychological process.

\subsection{Music Appreciation}

\subsubsection{The Development of Children's Music Appreciation Ability}

Music appreciation is an important part of music activities, which is an important way to let the children listen to music and play their imagination. In fact both at home and abroad have many studies show that in children born of that moment, the sound has reaction, more research pointed out that the baby in the prenatal period began to listen to, which is why the prenatal care. The current scientific evidence, the baby in the womb has indeed can hear outside noises. Germany's famous child musician Orff encourages children to sound out of the objects that are found in a sound. Children about 3 years old, has been able to as the music began to ups and downs, such as hearing tranquil melody, gently shake the body; hear the fierce strong melody, may begin to kick and a series of actions. For example, children in the process of music appreciation, the habit of using their expressions, action to make the music that was heard at that time. From 5, 4 years old, the type of music began to have more specific resolution, creativity will continue to strengthen, to some simple lyrics also began to understand the ability, can be based on their own songs to play some imagination. US Davidson once in 1985 for 1 - 7 years old children can master tone, range and other materials for research and analysis, he found that children's range of space is increase with age and gradually expand. From which we can get inspiration, children's appreciation ability can also be guided by the teachers, the formation of a number of different styles of songs and understanding.

\subsubsection{Basic Knowledge and Skills of Music Appreciation}

Hearing is one of the first sensory organs of the infant, and the infant is particularly sensitive to the sound emitted by the surrounding. Listening is a very important basic skill that children need to have. Such as the nature of a variety of sounds: wind and rain, thunder, a variety of small animals, such as the sound of the switch door. These are the children in the life of the music education in the life to hear the sound, that is, in the life to guide the child to listen to the voice of nature. Listen is no essential connection between the performance and the rhythm of life, but it is not essential to cultivate the children's ability to appreciate music, but in fact it is the basis for the cultivation of children's music appreciation ability [11]. After entering the formal education of kindergarten, children begin to listen to the musical instrument sound, and entered the song appreciation, to understand music songs of experience. Music appreciation is to allow children to play their own imagination in the concept of sound, so as to enter the music artistic conception. Children to understand the name of this song in the name of the song and playing musical instruments, then the songs are the main content and emotional changes, requirements for children only need to identify the happy or quiet, the last piece of the speed and strength, such as rhythm is urgent or slow.

\subsubsection{The Selection of Music Appreciation}

Choosing appropriate music appreciation is an important part of the children's appreciation activities, and it can be divided into Chinese. There are also instrumental works, which is conducive to expand the horizons of music for young children, from a relatively deep. No matter what kind of work, should be combined with the actual age of young children and personality characteristics, the form is simple. Simple structure, but the image is vivid, with a strong artistic and rich, so as to attract children's attention. As the Russian composer Prokofiev's 5 symphonic fairy tales Peter and the wolf 6, it is a magical and imaginative works. The children will hear being mixed with the sound of nature and small animals, thereby judging, this is a story happened in the forest, the protagonist is a boy, Peter and the wolf, the children listen to the melody of Peter lovely melody with a ferocious wolf said. It can also be a reflection of the image of the music through the visual material, can be a picture, video, but for young children, do not choose the video of the performance of the symphony, for they are too ab- 
stract. Paint, imagine the color of the forest, and add the color of the imagination to the picture.

\section{The Application Value of Music in the Early Childhood Education}

Preschool education is the starting point of a person's lifelong education, but also the starting point of quality education. Over the years, China has promulgated a series of laws and regulations on early childhood education are emphasized: the implementation of moral, intellectual, physical and aesthetic education, and promote the development of children's physical and mental harmony, as the basic requirements of child care education [12]. Early childhood education is a good foundation for the development of children's life, but also for the primary school education. Music education in early childhood education for people's quality, character has a profound role and far-reaching impact. Music education can lay a foundation for the perfect type of personality, but also can develop the whole brain function. Human brain left hemisphere to have the function of language, logic and abstract thinking. Any kind of art active is the result of the brain's left and right hemispheres, the age is small, the development potential is bigger. Spiritual life can't be separated from the music, because some of the human soul can only be illuminated by music. Coda believes that music has the power to mold character, and even to transform the human, the influence of the emotion of the people is difficult to replace any language.

\subsection{Promote the Development and Improvement of Children's Intelligence}

Physiologist and doctors believes that orderly rhythm, soft and beautiful music can cause of harmonic rhythm of the circulatory and respiratory, human body biological rhythm which affects children's growth and development and health modulation. Modern scientific research has confirmed that music can stimulate the activity of the brain cortex, and has a direct impact on the edge system and brain stem reticular formation, regulate brain function, promote the development of brain and sensory organs, improve children's ability of thinking and imagination, enhance and restore memory, and promote the development of intelligence and improve. In addition, music can also help balance the development of the left and right hemispheres of the brain. Music activities can make the left and right hemispheres of the brain communicate with each other and coordinate with each other. Foreign research found, that the excellent music class students, their math class is also very good. Music can also be very effective in improving children's imagination and creativity. Einstein grew up with music and music education, and lifelong indissoluble bound. He was 6 years old when he was able to play a musical instrument, and when he went to the Soviet Union, he was holding a violin in his hand. Einstein once said: "the music world has given me the intuition that my new discovery of the moving object has a great help" [13].

\subsection{Promote the Development of Children's Personality}

Music education active for young children's personality development has played a positive role, especially in the first performance in the character. Music activities in the rich sound, beautiful melody, vivid rhythm can let the child feel happy, immersed in the music of the sea of children, the heart is full of music, all the troubles will forget. In addition, children in the process of participating in music active need to work with peers, students, through this way, to increase the opportunity to communicate and cooperate with others, to share with others, more vivid character, more cheerful. Secondly, to participate in the music activities, children's physiological needs are met, have the opportunity to show up and get other people's recognition, which can make children feel the value of self-existence and self-value. Through the music performance, children can accumulate rich experience, each performance will be for children to add a sense of self-confidence, satisfaction, sense of self existence, and thus make their confidence to enhance the experience.

\subsection{Improve the Aesthetic Ability}

Music is wonderful, it is better than words. Children in the music sea, listening to the sounds of the melody can imagine their own colorful ice. Music is vivid and colorful; children feel the music at the same time, the spiritual beauty of music of baptism, purification of beauty, the beauty of feelings. Music can bring people unlimited potential of the beautiful picture, can make people feel cheerful, children often immersed in the music so beautiful picture, the aesthetic will be improved.

Music is the beauty of art, by music organization, through art creation, to reflect the life and expressed emotions and thoughts of the artistic image, it can be said, is the basic qualities of music aesthetic. Music education 
is based on the cultivation of children's aesthetic ability, which determines the content of music selection should be consistent with the characteristics of children's age, and in the form of children can accept the aesthetic ability of the training. Music education in kindergarten is derived from the actual life of the children, and closely related to children's life experience, can be better understood and accepted by children, but also easier to stimulate the initiative of the children's active learning and actively explore their awareness. More effectively stimulate the positive feelings of young children. In this process, the power of the music into the children's minds, so as to cultivate their noble music sentiment, improve the ability of children to feel the music, music and music performance.

\subsection{Conducive to the Formation of Children's Perfect Personality}

Through music, not only enhance children's aesthetic education, but also can exercise their will, promote the formation of the moral character and spirit of their good health, so as to lay a foundation for the formation of perfect personality. Japan Association for the education of young children tracking survey showed that children from baby come to accept and love music grew up in the little misdeed character; they will become more kind and honest. Nearly nine of the senior executive of the US Congress and the top executives of the five hundred companies have learned music in their infancy. It can be seen that the musical training of the early childhood, to the future of the character formation, and even to improve leadership skills have a very big help.

A famous Japanese music educator said: "the music education is not to cultivate a few of the great and outstanding talents. But through the music education, every child is promoted to have a noble heart and perfect personality, and in fact this is the goal that every person should pursue.” [14]. Kong Zi think: stand up ceremony into music. Is to achieve through the music art of self-cultivation to complete a kindly man of high character, coordination of human knowledge, experience, promote the harmony, the overall improvement and development. Ancient Greek philosopher Democritus also believes that the arts, music is an important means to change people, creating a person. He advocated music education for children, it is necessary to pay attention to talent, also want to emphasize diligently, in children learning skills and cultivate their willpower, purify the mind. Century Japan famous educator Mr. Suzuki is emphasized in the music education training, exercise children's willpower, perseverance, to overcome difficulties and unremitting efforts.

\section{Conclusion}

In today's society, the popularization of children's music quality education is becoming more and more important, and the education effect of the music enlightenment education is also incomparable [15]. Learning music not only can help children's intelligence and moral character to be improved (music can show the child's nature, and will have a positive impact on their personality development) but also can improve the children's music and cultural quality and aesthetic ability, accept and create music culture, and then make the sentiment to improve the personality. In the process of music education, the teachers, students and parents of the joint efforts of the three can better achieve the goal of early childhood education. It is also better to realize the value of music for children's enlightenment education.

\section{References}

[1] Zhang, S.T. and Chi, X.X. (2011) On the Enlightenment of Orff Music Teaching on Chinese Music Education. Henan Institute of Science \& Technology, Xinxiang.

[2] Moerman, D.M. (2015) The Buddha and the Bathwater: Defilement and Enlightenment in the Onsenji engi. Japanese Journal of Religious Studies, 42, 71-87. http://dx.doi.org/10.18874/jjrs.42.1.2015.71-87

[3] Yue, L.U. and Psychology, S.O. (2014) Progress in Music Cognitive Research and Its Enlightenments to Education. Guide of Science \& Education, 4, 171-172.

[4] Tian, S. (2011) The Enlightenment of Xun Zi’s Theory of Music on Music Education in Vocational and Technical Colleges. Southern Vocational Education, 1, 79-83.

[5] Wang, J. (2013) The Evolvement on Research Topic of Exquisite Course and Its Enlightenment for Construction of Exquisite Resource Sharing Course. Modern Educational Technology, 23, 95-99.

[6] Mei, Q.I. (2011) An Exploration of Children’s Piano Enlightenment Education. Shandong Women's University, 4, 8082. 
[7] Pang, H.B. (2010) The Current Situation and Enlightenment of School Mental Health Education in the USA, the Great Britain and France. Educational Science of Hunan Normal University, 9, 112-115.

[8] Li, R.W. (2004) The Education of Music and the Way of Enlightenment to Children. Beijing Youth Politics College, 13, 44-49.

[9] Hewitt, J.R. (2011) The Age of Enlightenment. Money Marketing, 10, 91.

[10] Zheng, Y. (2013) A Summary of PIRLS Study and Its Enlightenment on Compilation of China's Primary School Chinese Textbooks. Curriculum Teaching Material \& Method, 6, 20.

[11] Li, Y. (2010) Ideas and Inspiration on Cheng Heqing’s Children’s Musical Education. Shangdong Yingcai University, Jinan.

[12] Tan, L. (2011) What’s So Important about Music Education? (Review). Music Education Review, 19, 201-205.

[13] Caradonna, B.J.L. (2012) The Enlightenment in Practice. Cornell University Press, Ithaca.

[14] Yu, M.A. (2012) British Social Security Management Mode and Its Enlightenment to China. Shenyang University, Shenyang.

[15] Ning, J.I., Music, S.O. and University, Z.N. (2014) Analysis of Li Jin-Hui’s Ideas on Children’s Art Education and Its Contemporary Value. Beijing Dance Academy, Beijing. 